\title{
Plasma bubbles: a route to sustainable chemistry
}

\author{
Jungmi Hong ${ }^{1,2}$, Tianqi Zhang ${ }^{1}$, Renwu Zhou' ${ }^{1}$, Rusen Zhou ${ }^{1,2}$, Kostya (Ken) Ostikov' ${ }^{2}$, Adel Rezaeimotlagh ${ }^{3}$ and \\ Patrick J. Cullen ${ }^{1 *}$
}

\begin{abstract}
Atmospheric plasma discharges are finding increased applications in addressing environmental challenges including water purification, chemical synthesis and biotechnology. An effective means of interfacing the reactivity of plasma gas discharges with liquids is needed to enhance liquid phase chemical reactions. Plasma discharges in bubbles has been considered as an innovative solution for achieving this goal potentially offering electrically driven, sustainable chemistry with low energy consumption and the unique benefit of maintaining a large volume discharge under the liquid surface. Here we provide a concise review on the state-of-art for research on plasma-bubble interactions and a perspective for future research.
\end{abstract}

Keywords: Plasma bubble, Plasma-liquid interaction, Plasma assisted chemical processing, Sustainability

\section{Introduction}

The benefits of interfacing plasmas and liquids are increasingly being recognized, especially in environmental applications including; water treatment (PWT-plasma water treatment), loading and delivery of reactivity in water (PAW-plasma-activated water) and in solutions (PAS-plasma-activated solutions), and the synthesis of useful chemicals or nanomaterials [1-3]. There are numerous approaches for interfacing a plasma phase and a liquid phase including direct impingement to the free surface with plasma jets or spark discharges, the diffusion of afterglow species to the liquid, the introduction of vapour or droplets to the gas phase or use of 'plasmabubbles'. Here, we discuss the approach of inducing plasma discharges within gas bubbles.

The unique benefit of plasma discharges in bubbles is the facilitation of large volume plasma in water/liquids with reduced breakdown voltage and energy consumption [4]. Plasma bubbles have been considered to be useful for many applications, such as water purification,

\footnotetext{
* Correspondence: patrick.cullen@sydney.edu.au

${ }^{1}$ School of Chemical and Biomolecular Engineering, University of Sydney,

Darlington, Sydney, New South Wales 2008, Australia

Full list of author information is available at the end of the article
}

chemical synthesis and, more recently, medicine and biotechnology, that require stable plasma discharges in liquid or at the gas-liquid interface [5-12]. Compared to the typical plasma discharge over the liquid surface [13], underwater plasma bubbles can provide an intensified gas-to-liquid mass transfer, thus enhancing the production and transportation of aqueous reactive species for specific applications, due to the large interfacial areas, long residence times and high internal pressures [4, 9]. Moreover, the burst of fine bubbles can potentially produce mechanical agitation and local heating, leading to the localized formation of additional reactive radicals in an aqueous solution [6].

Locke and Shih [14] presented comparison data between a plasma-bubble system and a plasma discharge over a water surface and direct discharge in the water for $\mathrm{H}_{2} \mathrm{O}_{2}$ synthesis. Approximately, $1 \mathrm{~g} \mathrm{kWh}{ }^{-1}$ of higher energy efficiency for the plasma-bubble case was found and attributed to the enhanced mass transfer with the extra benefit of minimizing electrode erosion by using a reduced applied voltage. In a specially designed bubble injection configuration, by applying sub $\mu$ s width short pulses at higher applied voltages, it was found that further improvement $\left(8.4 \mathrm{~g} \mathrm{kWh}^{-1}\right)$ could be achieved in 
$\mathrm{H}_{2} \mathrm{O}_{2}$ energy efficiency. Zhou et al. developed an argon plasma-catalytic bubble reactor to generate underwater plasma bubbles for efficient delivery of reactive species for $\mathrm{H}_{2} \mathrm{O}_{2}$ synthesis, with the highest $\mathrm{H}_{2} \mathrm{O}_{2}$ production rate and energy efficiency of $164.6 \mathrm{mg} \mathrm{h}^{-1}$ and $9.0 \mathrm{~g} \mathrm{~kW}$ $\mathrm{h}^{-1}$, respectively [5]. Recent advances in the plasmadriven electrochemical conversion application such as NOx production, demonstrated a significant improvement in NOx energy efficiency up to $15.6 \mathrm{~g} \mathrm{kWh}^{-1}(3.8$ $\mathrm{kWh} \mathrm{mol}^{-1}$ ) using a plasma bubble column reactor [10], which is at least three times higher than comparable reported studies [15]. Considering the potential for effective scaling (both vertical and horizontal) and the performance of plasma bubbles (in terms production rates and energy efficiency), the technology is gaining interest, particularly in water purification and plasmaassisted electrochemical conversion [15].

However, despite these achievements and progress in applications, the understanding of the underlying physics and chemistry is lacking, arising from the complexity of this multi-physics, multi-scale problem of dynamic plasma discharges in the gas bubble immersed in a liquid. There have been significant research efforts in different aspects to investigate the plasma-liquid interaction involving a broad research community of plasma physics, aerosol science, chemistry, radiolysis, fluid dynamics, etc. [1].

Most of the scientific focus surrounding plasmabubble systems has been on the plasma interaction with water at the interface. There have been a few papers dedicated to providing an overview of the interdisciplinary subject of plasma-liquid interactions, which identify the important research challenges of the subject including the developments in diagnostics, modelling and fundamental cross sections and reaction rate databases $[1$, 16, 17]. From this extensive research work on plasmaliquid interactions, we will selectively introduce and discuss research works to provide a better understanding of plasma-bubble discharges from the engineering and physicochemical aspects.

\section{Plasma reactor configurations}

The types of plasma bubble reactor configurations can be divided into two main groups, with gas inlet or without. Most plasma bubbles studies have a gas inlet, which allows varying conditions of gas properties and electrode positioning, giving more degrees of freedom to the configuration design. As shown in Fig. 1, various studies have illustrated the applications of utilizing plasma

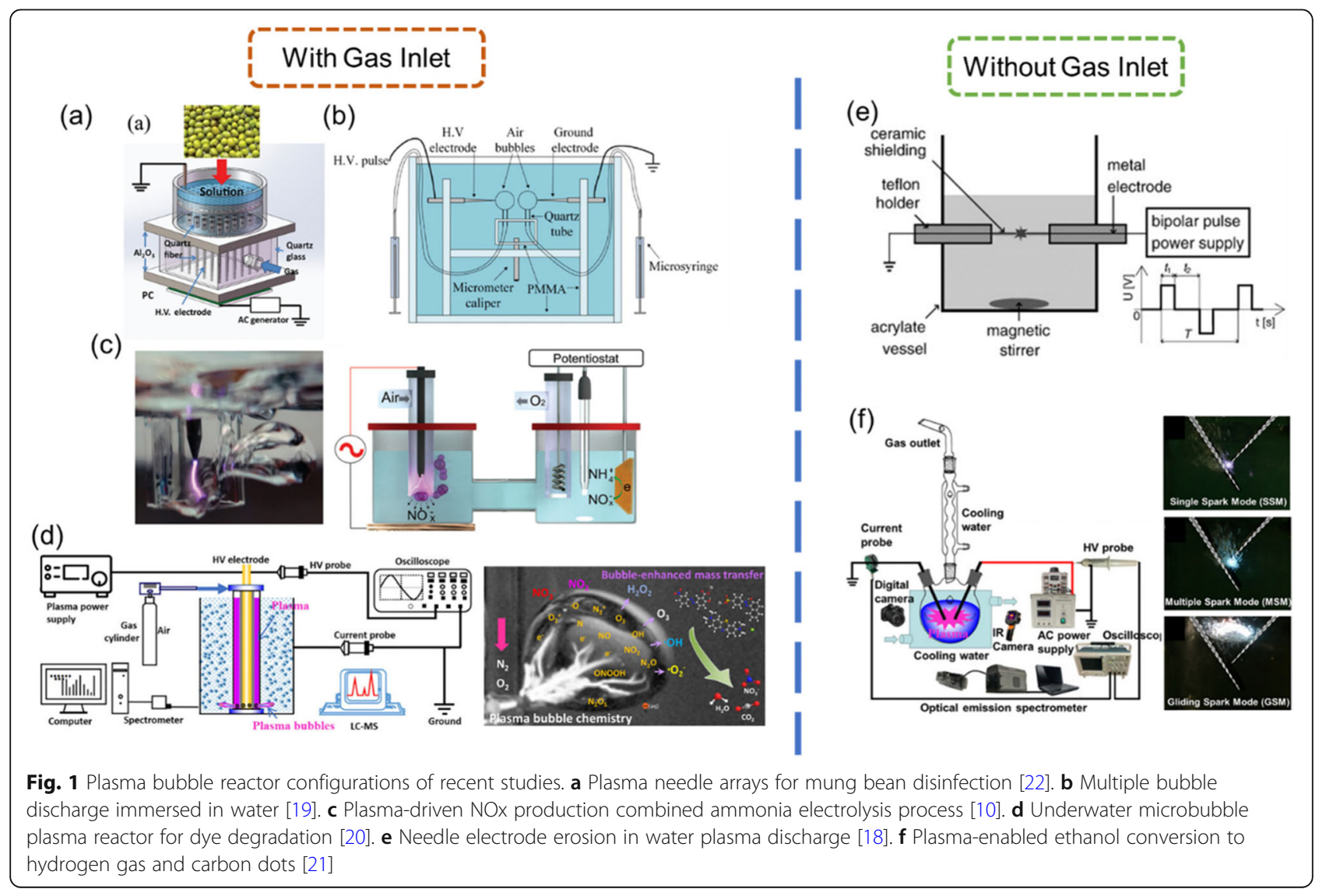


bubbles for disinfection, NOx production, wastewater treatment, biomass conversion, etc. [10, 18-22].

There are several design parameters of the plasma bubble reactor to consider. Gas-related factors, including gas type, flow rate, velocity and gas aperture, are closely related to the formation of bubbles that may affect the total mass transfer and activity of plasma reactive species including bubble size distribution. Zhang et al. discussed the effect of plasma bubble mass transfer on the degradation of antibiotics [23]. In addition, Sun et al. applied Raschig rings in a bubble column reactor to enhance adsorption and mass transfer by enlarging the mass transfer area and extending residence times [10]. The other important factor is the electrode, where electrode material, shape, and position are found to influence the discharge modes and characteristics. The positioning of pin-to-pin electrodes has been studied by $\mathrm{Tu}$ et al. using a high-speed charge-coupled device (CCD) camera [19, 24]. Their study categorized the breakdown into three types depending on the position of the bubbles and the electrodes. Potocký et al. studied the effects of stainless steel and tungsten electrodes on discharges in water without gas input, finding that the material properties can influence both discharge mode and electrode erosion [18].

From the engineering point of view, the important design parameters of plasma bubble reactors are structure complexity, scalability and economic feasibility. The structure and its complexity lay the foundation of the basic plasma characteristics, and normally are governed by the components and its materials, which further affects the economic feasibility and scalability. The scalability which can be defined as the ability to attain larger/smaller scale production by changing individual productivity or unit numbers in the respect of plasma engineering does not follow a linear scaling relationship between the production rate and voltage/current. Thus, the most popular approach is maintaining a small/ medium scale optimized plasma reactor and creating an array of units. When it comes to the economic feasibility of plasma bubble reactors, in addition to scalability, production rate and energy efficiency are important factors. In a plasma chemical process, most common energy loss comes from Joule heating and relaxation of vibrational and transitional state molecules. As for the industrial practice of plasma technology, energy consumption, especially energy efficiency, is critical. Optimization of plasma discharge parameters and adoption of advanced pulse power supplies can be a solution.

\section{Transport of reactive species}

The challenges of understanding the plasma discharge within the bubble principally lie in the interactions at the interface of the bubble and the liquid. For instance, the mechanisms in which the energy of electrons, ions, and reactive radicals can be sustained and transported across the plasma-liquid boundary along with quantifying the lifetimes of these species. Similarly, an understanding of the important physical and chemical pathways which influence the bulk liquid chemistry by the injected plasma species including highly reactive eare important. As with the central role of e- found in gas phase plasma physics and chemistry, solvated e- is considered to be pivotal, as a smallest primary reducing agent and highly reactive intermediate in various fields including environmental chemistry, charge-induced reactivity, reprocessing of nuclear waste and biological effects of radiation [25-27]. The physical and chemical properties of solvated electrons have long been investigated mainly using high energy electron beams or pulse radiolysis with a significant research interest. Some studies suggest a high solvation energy barrier of electrons of $-156 \mathrm{~kJ} / \mathrm{mol}$ [28]; however, other studies, including experiment and theoretical simulation works, suggest fast solvation of electrons in fs with 100 ps order of lifetimes and penetration depths of $10-20 \mathrm{~nm}$ for an electron energy range of $1-10 \mathrm{eV}$ [27, 29-32]. Except for about a $10 \%$ possibility of existing in the vapour phase above the interface, Uhlig et al. [33] demonstrated that fully hydrated surface electrons are mostly buried in the interfacial water layer by employing ab initio molecular dynamics simulation as shown in Fig. 2. In a plasma discharge inside a bubble, it is expected that the majority of the electrons will be quickly solvated in the water as shown in recent plasma modelling dealing with plasmabubbles or other liquid interfaces [34-37].

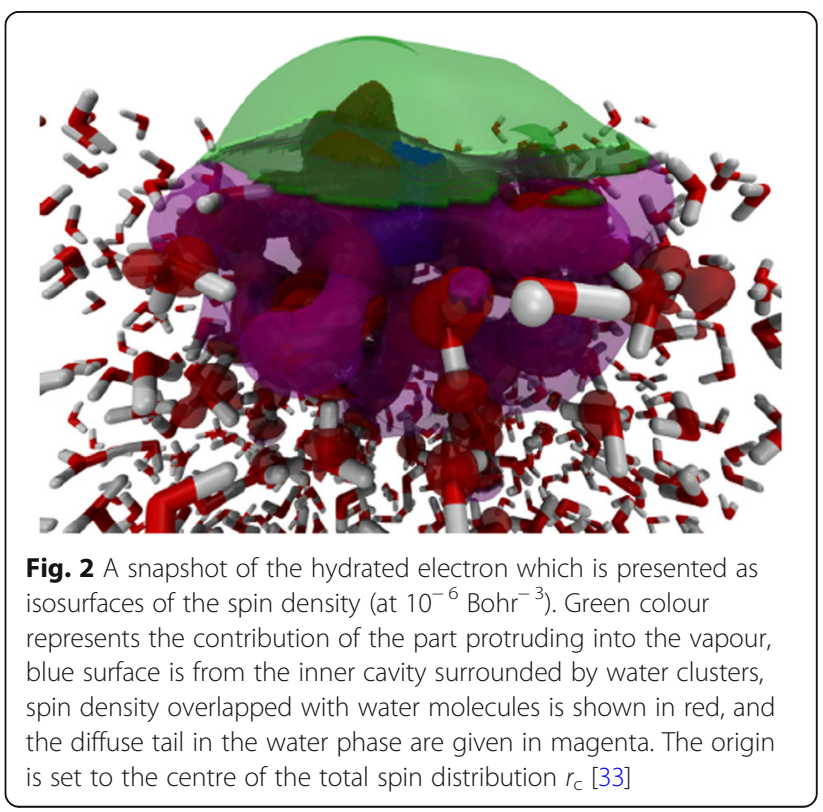


Some reports have discussed the impact of high energy electrons in plasma-liquid interactions. Levko et al. [38] reported that propagating streamer heads on the liquid interface can cause ionization of water by energetic electrons. Additionally, a possible ion-rich sheath formation on the gas side in the vicinity of the interface of water was proposed. It may implicate various excitation, dissociation and chemical reactions which require relatively high energy barriers, all of which are possible as in gas phase plasma discharges. However, it is worthwhile to note the different characteristics of interfacial and liquid phase reactions which are based on much stronger interactions with each other and also the high probability of multi-body reactions rather than two body interactions unlike those of typical gas phase reactions [15].

Ions are also considered to be solvated in ps orders of time and vibrational relaxation can occur in the following 10-100 ps [1]. Despite the expected important roles of ions in the plasma-liquid interface, fundamental data from experimental measurement are limited. However, generally low temperature atmospheric pressure plasma systems provide ion energies of only several $\mathrm{eV}$. Minagawa et al. showed using simulations by classical MD modelling that the atomic oxygen ion can sputter water molecules but only penetrate to a maximum of 1.2-2.8 $\mathrm{nm}$ for an eV range of 10-100 [39]. The effective charge transfer collisions of low energy ions $(0.1-10 \mathrm{eV})$ such as $\mathrm{O}^{+}, \mathrm{Ar}^{+}, \mathrm{N}_{2}^{+}, \mathrm{N}^{+}$and $\mathrm{Kr}^{+}$with water molecules has been demonstrated where the cross section has approximately $10^{14} \mathrm{~cm}^{2}$ at $0.1 \mathrm{eV}$ with energy dependence of $\mathrm{E}^{-0.5}$ [40-43]. Tochikubo et al. reported high-density $\mathrm{OH}$ - ion production by e- and $\mathrm{H}^{+}$production by positive ions and suggested a possible mechanism for the initial stage of liquid reaction by incident electrons and ions in both high and low energy states [44]. Despite the limited life times and effective penetration depths of e- and ions in plasma-bubble interactions, their impact and importance cannot be underestimated in driving the chemical reactions in the bulk water media. In addition, it is also important to consider the possible bi-directional transport of reactive species from the liquid to gas (bubble) region as Bruggmann et al. [17] discussed based on the optical emission measurement results showing the presence of high density $\mathrm{OH}$ radicals on the top of the water surface $[45,46]$.

Along with the electrons and ions, from the gas phase plasma discharge region, high-density neutral but reactive species are supplied into the plasma-liquid interface. As Bruggmann et al. [1] commented, there is an analogy between plasma-liquid interaction and plasma-solid surface interaction. Scattering, adsorption, absorption into the liquid and desorption can be considered as well as Langmuir-Hinshelwood and or Eley-Rideal interactions $[47,48]$ at the plasma-bubble interface surface.
Molecular dynamics simulation can provide information on the penetration depth of radicals and molecules as they interact with a large number of water molecules at the interface and induce further chemical reactions [49, 50]. Minakata et al. provided the aqueous phase $\mathrm{HO}$. rate constants for a number of elementary reactions using GCM (group contribution method) [51] which was proven to be reliable for the prediction of gas phase reaction coefficients for compounds with a wide range of functional groups. Among the valuable discussion provided by Minakata et al., it is worthwhile to note there can be a drastic change in the reaction mechanisms in aqueous phase reactions to those in gas phase reactions due to the polarity and the hydrogen bond of water molecules [51]. In order to understand the macro scale measurements of densities or production rates of different aqueous products, Henry's law constant [52] and diffusion coefficient [53] in water can be used to provide useful data for plasma modelling. Different solubility and diffusion properties of various gas species is often used to explain the differences in the predominant species from the gas phase and observed in the liquid phase.

A feature of plasma-bubbles are their high gas-liquid interfacial areas, which lead to greater species mass transfer rates. The interfacial area is inversely proportional to the bubble Sauter mean diameter; smaller bubble size is associated with a larger interfacial area, favouring gaseous plasma species mass transfer to liquids. Therefore, enhancing micro-size bubbles in the plasma bubble systems and integration with the microbubble technique is of particular interest for maximizing species mass transfer and mixing as well as further using the strong mechanics effects when bubbles shrink and burst, which are expected to sustain high density reactive species (OH in particular) in solutions. For example, plasma species from a DBD coupled with microbubbles (MB) from a MB generator has been proved to be highly efficient for contaminant removal and TOC reduction in water compared to the separated treatments with DBD and $\mathrm{MB}$, due to the enhanced $\mathrm{OH}$ generation in water, which was confirmed by ESR analysis and scavenger addition [54]. Also, plasma-loaded or activated microbubbles can enhance the dissolution of reactive chemical species, as evidenced by the doubled production of nitrite and ozone and 3-time increased nitrate synthesis rate as demonstrated by $\mathrm{Wu}$ et al. [55].

The existence of moderate concentrations of $\mathrm{H}_{2} \mathrm{O}$ in the discharge area benefits the formation of $\mathrm{OH}$ radicals both in the gas and at the gas-liquid interface via $\mathrm{H}_{2} \mathrm{O}$ dissociation, water-electron and water-energetic gas species collision and reactions, etc. It has been shown that the formation of $\mathrm{OH}$ radicals and their diffusion into water are crucial for the aqueous $\mathrm{H}_{2} \mathrm{O}_{2}$ formation. Thus, $\mathrm{H}_{2} \mathrm{O}_{2(\mathrm{aq})}$ is generally an important and inevitable long- 
life species obtained with plasma bubbles or retained in thus-treated water if no $\mathrm{OH}$ scavengers or chemicals consuming $\mathrm{OH}$ exist in the water. The concentration of $\mathrm{OH}$ radicals at the gas-liquid interface is of significance to produce $\mathrm{H}_{2} \mathrm{O}_{2(\mathrm{aq})}$ both for discharges over water and in plasma bubbles, while the contribution of $\mathrm{H}_{2} \mathrm{O}_{2}$ formed in the gas phase is observed in higher number density than $\mathrm{H}_{2} \mathrm{O}_{2(\mathrm{aq})}$ due to the higher content of water vapour in the discharge zone $[8,56]$. Higher $\mathrm{H}_{2} \mathrm{O}_{2(a q)}$ production rates and energy yields have been observed by using plasma bubbles with the increased humidity proven to be beneficial to enhance the production of $\mathrm{H}_{2} \mathrm{O}_{2(\text { aq) }}$ for both plasma bubbles and over-water discharges $[8,14]$. When air or nitrogen-rich gas is used as the reactants, the products include excited $\mathrm{N}_{2}$ and $\mathrm{O}_{2}$ at different energy states, dissociated $\mathrm{N}, \mathrm{O}$ atoms which then interact further to form $\mathrm{NO}_{x}$, such as $\mathrm{N}_{2} \mathrm{O}, \mathrm{NO}$, $\mathrm{NO}_{2}$, etc., depending on the composition of $\mathrm{N}_{2} / \mathrm{O}_{2}$ and other discharge and processing parameters. The inert property of $\mathrm{N}_{2}$ poses significant challenges for its dissociation and the following reactions to harvest targeted chemicals. In this point of view, non-thermal plasma still suffers from unsatisfactory conversion rates, product yields and energy efficiencies in nitrogen fixation applications. Recently, a plasma bubble column reactor combining glow and spark discharges was developed and featured with an aqueous NOx- production rate of 3 $\mathrm{mmol} / \mathrm{h}$ and an energy yield of $3.8 \mathrm{kWh} / \mathrm{mol}$ [10]. The weaker glow discharge not only initiated and assisted $\mathrm{NO}_{\mathrm{x}}$ formation but also contribute as a gas preactivation step increasing the internal energy of stable $\mathrm{N}_{2}$ molecules before transport to the high electron energy and density spark region, securing sufficient activation while not requiring much further energy inputs.

Figure 3 summarizes and illustrates the possible physico-chemical reactions in plasma bubbles as an example of $\mathrm{H}_{2} \mathrm{O}_{2}$ formation and nitrogen fixation processes. Bubbles containing energetic electrons and plasma-generated activated gaseous species create a reactive environment with significantly low energy input under water. These species then undergo further interaction such as charge transfer, quenching and others chemical reactions during the plasma propagation, once reaching the gas-liquid interfaces, in which the influences from liquids such as the increased water vapour or other impurities from liquids through diffusion and evaporation matter, they are expected to encounter more complicated physical and chemical processes before some of them transfer, permeate and enter the bulk liquids $[1,3]$

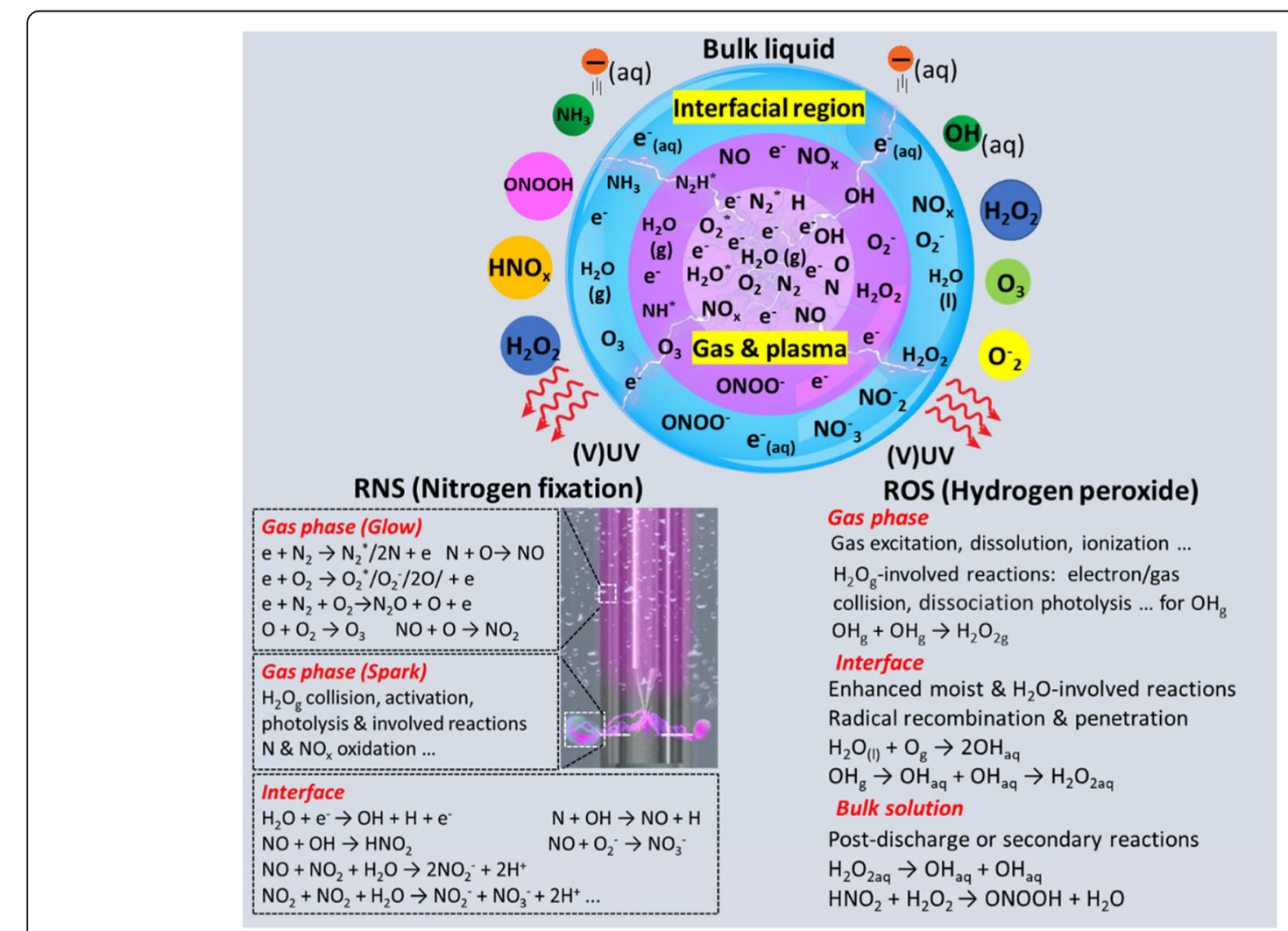

Fig. 3 Reactive species generated and typical reactions involved at different stages for $\mathrm{H}_{2} \mathrm{O}_{2}$ formation and nitrogen fixation using air plasma bubbles. Adapted and modified from Sun et al. [10] 
Additionally, there are some important properties of the liquid, such as $\mathrm{pH}[57,58]$, temperature [59] and electrical conductivity $[60,61]$, that can affect the discharge characteristics, plasma chemistry and the efficiency of the process [62]. Although the individual application and the target compound determine the favourable $\mathrm{pH}$ condition, numerous studies reported the importance of the liquid $\mathrm{pH}$ on plasma chemical reactions. For instance, Wang et al. [57] reported that the removal rate of $\mathrm{P}$-chlorophenol increased in alkaline $\mathrm{pH}$ due to higher hydroxyl radicals and a greater reaction constant with ozone at this condition. Xin et al. [58] investigated the effect of $\mathrm{pH}$ on hydrogen production and reported higher concentrations of hydrogen at acidic condition. This is due to the presence of $\mathrm{OH}^{-}$in alkaline conditions, which can generate $\mathrm{O}_{2}$ and hinder the production of $\mathrm{H}_{2}\left(4 \mathrm{OH}^{-}-4 e^{-} \rightarrow 2 \mathrm{H}_{2} \mathrm{O}+\mathrm{O}_{2}\right)$.

Plasma reactive species possess acid-base equilibriums between themselves that, based on the $\mathrm{pH}$ conditions, can lead to various reaction pathways. In water/wastewater treatment applications, hydroxyl radicals (oxidizer) in alkaline conditions can be converted to $O^{-}$, which compared to $O H$ represents a different chemical reactivity $[59,63]$. Further, the reactive species act differently with organic molecules thus result in different degradation rates and efficiency. For instance, a high efficiency in phenol removal using a pulsed discharge plasma reactor was reported at $\mathrm{pH} 10.2$ [64].

The electrical conductivity of the liquid affects the characteristics of the plasma discharge and consequently, the generated reactive species $[61,65]$. It was reported by Yang et al. [66] that the discharge mode varied from spark to spark-streamer and further to corona when the conductivity of the liquid increased in a pulsed discharge process. The streamer discharge can be lengthened and leads to the induction of spark by decreasing the conductivity. This is important as a spark discharge results in an enhanced reactive environment due to the presence of high -energy particles, UV radiation, etc.

Lai et al. [60] reported that the conductivity affected the propagation of the discharge inside bubbles due to differences in relaxation time and charge carriers at different conductivities. At low conductivities, the surface charge, as the dominant effect, prevents propagation discharge in the bubble. In contrast, at high conductivities the charges move at a faster rate and lead to interfacial streamers, which can stop axial streamer. Although the generated reactive species may be more at high conductivities, the energy efficiency is lower as the energy dissipation is higher due to greater levels of current [61].

The concentration of $\mathrm{OH}$ increases by increasing the conductivity since it can provide stronger discharges. However, very high conductivities can pass higher levels of current, which consequently result in a higher plasma temperatures and lower rates of generated reactive species. Furthermore, the presence of inorganic ions, such as $\mathrm{Cl}^{-}, \mathrm{NO}_{2}^{-}$and $\mathrm{HCO}_{3}^{-}$, that maintain the conductivity of the liquid can react with $\mathrm{OH}$ and produce compounds that are not active for degradation [59].

Temperature of the liquid is another important parameter affecting the efficiency of a plasma bubble process, especially in water treatment applications, as it can determine the concentration and lifetime of the generated reactive species [67]. For instance, Chen et al. [68] reported higher phenol degradation rates at lower temperatures in a batch discharge unit using oxygen bubbles. Another study indicated that at lower temperatures for decolouration of methyl orange are desirable [69]. Based on Arrhenius equation, at relatively higher temperatures hydroxyl radicals, which are a major agent in plasma oxidation process, can rapidly be quenched by abundant molecules, such as $\mathrm{H}_{2} \mathrm{O}$, and consequently reduce the degradation rates [59].

\section{Diagnostics}

On top of the difficulties of studying complex plasmaliquid interactions, diagnostics of rapidly evolving plasma discharges in $\mathrm{mm} / \mu \mathrm{m}$ scale bubbles adds an even greater challenge. Fast imaging can provide straightforward monitoring data of time evolution of the plasma discharge within and near the bubble volume. The streamer propagation across the bulk liquid from the metal electrode was investigated with a disruption of the bubble observed due to the substantial energy transfer from the discharge [4]. It is considered that as the streamer propagates along the bubble surface it transmits electric, acoustic and thermal stresses. Therefore, it perturbs the bubble surface upon impact and can destabilize the shape depending on the applied electric field strength. In the case of plasma discharges excited in bubbles that are attached to the electrode, a resonant wave structure on the bubble surface has been observed [70]. Figure 4 shows a 'surface hugging' streamer along the interface of the bubble in between the counter pin electrode [24]. Spatial electric field distribution for the given configuration, especially the local electric field around and inside bubble is considered to be the most important governing factor for the following breakdown events and discharge pattern either inside or at the interface of the bubble [71, 72].

Fast camera imaging can also provide extended information for controlled experimental parameters. Moon et al. [73] shows how the liquid water can influence the plasma discharge by varying $\mathrm{pH}$ and conductivity of water with plasma treatment time. The influence of a solid surface which is a substrate for the deposition or modification to the plasma characteristics has been 


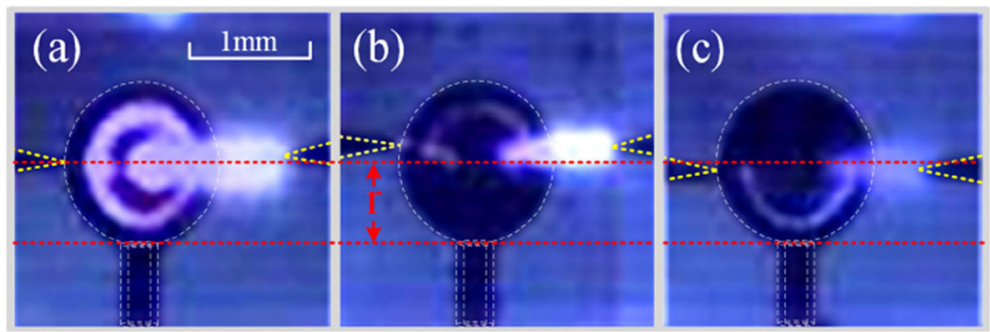

Fig. 4 Influence of vertical position of electrodes to discharge in gas bubble [24]

commonly observed and known including Schröder et al [74] who showed the altered distribution of atomic oxygen and reactive oxygen species (ROS) with different surface conditions for samples exposed to a plasma jet using two-photon absorption laser-induced fluorescence (TaLIF). In the case of longer treatment times, a larger deformation of the water surface was observed under the same applied electric field due to the decreased surface tension and increased conductivity caused by increased $\mathrm{H}^{+}$and $\mathrm{NO}_{3}{ }^{-}$densities in the water. This increased the electrical conductivity and decreased the gap distance by the deformation of the water surface, caused higher discharge current and led to the forming of spark-like discharges from an initial glow-like discharge condition. It suggests that for the local interface of a plasma-bubble discharge and liquid water, a similar physical mechanism can be applied, where increased ionic species at the interface and deformation of the bubble instantaneously influences the plasma properties and could lead to a transition to strong spark discharge.

Thomson and Rayleigh scattering and laser induced fluorescence or absorption techniques are well-established techniques for measuring the spatial distribution of electron density, accurate gas temperature and short-lived radical species fluxes such as $\mathrm{H} \cdot$ and $\bullet \mathrm{OH}$ measurement in the gas phase [75-78]. Optical diagnostics including various emission and absorption spectroscopy are common techniques for plasma-liquid interaction studies. However, Bruggeman et al. [1] commented on the possibility of degraded resolution by time averaging when the plasmas condition is not reproducible in space or time as for the conditions of spark or streamer discharges which are often the case for the plasma-bubble discharge.

A time integrated diagnostics on solvated electrons in water was possible by measuring inherent optical absorbance properties of solvated electrons at $\sim 700 \mathrm{~nm}$ [31]. Only a limited $12.5 \mathrm{~nm}$ (corrected in Corrigendum) of penetration depth of electron was observed indicating fast solvation before reacting through second-order recombination and discussed the possible impact of intense electric field at the interface of plasma and liquid with the evidence of an unexpected blue shift of the absorbance signal.
Considering the further spatial confines of plasma discharges in small bubbles and their common instability, those well-established various optical diagnostics may not be applicable or at least may requires careful consideration in performing the diagnostics and interpreting the results.

In situ electrochemical TEM can be an innovative approach that may be extended to investigating plasmabubble discharges [79]. An electrochemical cell inserted inside a TEM chamber equipped with thin SiN window cell allows the electron beam transmission, although for the status of the technology, it is a concern that the strong interaction of the electron beam with the material inside the cell, electrolyte and electrode material could limit the reproducibility and accuracy of the data. Adding significantly higher voltages to the cell may elevate the difficulties to another level. However, as we consider adopting the concept from a miniaturized plasma cell with an embedded bubble within, the required breakdown voltage for the scaled-down structure will be significantly lower. Figure 5 shows an example of a small size electrochemical cell for confocal microscope imaging [80] with further miniaturization possible by adapting photolithography [81, 82]. A compact and flat configuration of a plasma-bubble cell may open up the possibility of monitoring under different spectroscopy setups including SERS (surface enhanced Raman scattering). By mixing low concentrations of nanometal particles, such as nanogold or nanosilver, which can enhance the Raman signal from the adsorbate molecules, there may be an opportunity to monitor the chemical evolution of the plasma-bubble system from a new different perspective.

In addition, from Shiek et al., it would be a useful concept to adapt the idea of monitoring charged particle transport under an applied electric field, as shown in Fig. 5c. By monitoring the spatial charge distribution of the fluorescent dye (FITC-fluorescein isothiocyanate), it enables the monitoring of the spatial distribution of ionic species produced, such as $\mathrm{H}^{+}$and $\mathrm{OH}^{-}$, at and near the electrode.

Investigations on the long-lived chemical products dissolved in water are of fundamental importance to 

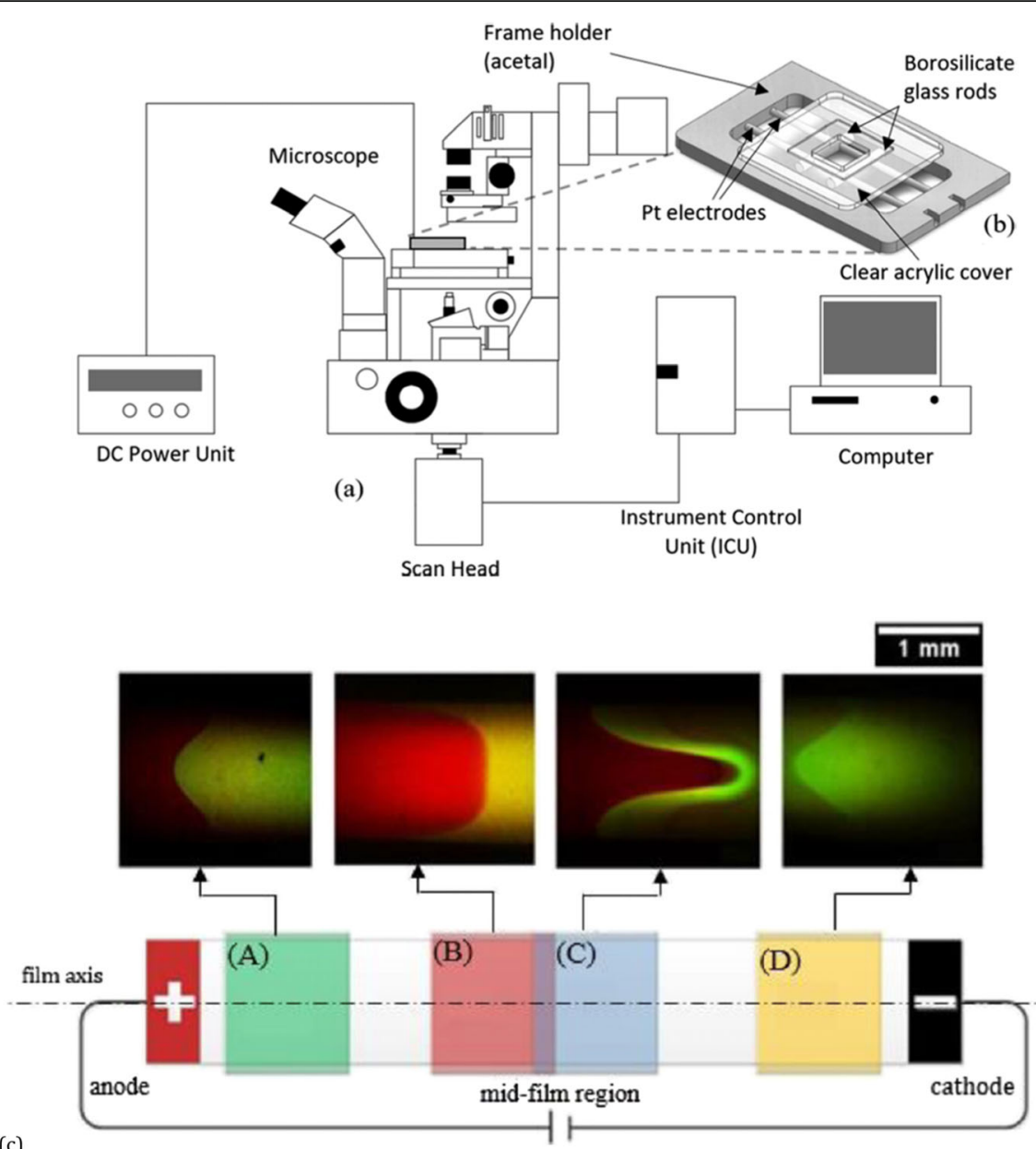

(B)

(C)

(D)

(c)

Fig. 5 Experimental setup for monitoring electrokinetic transport of a charged dye. a Confocal laser scanning microscope. b Film holder for suspending the free liquid film horizontally. c Dynamic nature of the dye separation front in a freely suspended liquid film under an applied electric field observed using confocal laser scanning microscopy. The emission colours red and green represent rhodamine B (RB) and fluorescein isothiocyanate (FITC), respectively [80]

understand the underlying mechanisms of plasma-bubble systems, with many studies reporting on the measurements of the bulk solution properties for plasma-liquid interaction [17]. The chemical probing technique employing specific scavengers combined with UV/Vis spectroscopy can be useful by enabling the evaluation on the concentration and production rate of chemical products in the liquid [83-86]. Hence, by measuring the specie densities of interest, the important chemical pathways can be elucidated for the long term chemistry of plasmabubble systems [7-9]. Bruggmann et al. provided details on different detection methods and scavengers including; $\mathrm{H}_{2} \mathrm{O}_{2}, \mathrm{OH}, \mathrm{O}_{2}^{-}, \mathrm{NO}_{2}{ }^{-}, \mathrm{NO}_{3}{ }^{-}, \mathrm{ONOO}^{-}$(peroxynitrite) and singlet delta oxygen $\mathrm{O}_{2}\left(\mathrm{a}^{1} \Delta_{\mathrm{g}}\right)[1]$.

\section{Computational study}

Due to the significant complexity of the physics and chemistry at the interface of bubble discharges with water, the use of computational modelling is valuable for interpolating unseen aspects of experimental diagnostics results and shed light on the underlying mechanisms of what it is observed. Again, in order to improve the accuracy of the computational modelling, some data from the fundamental properties may rely on sophisticated diagnostics results. Needless to say, experimental and theoretical studies are closely interrelated. Bruggeman stressed that ultimately the intermolecular attractive and repulsive forces are the governing factors for all the dynamic mass and energy transport at the interface and important of macroscopic properties such as surface tension [1]. In that perspective, the contribution of molecular/atomic level modelling has been particularly important, especially in understanding of solvation of gas species including electrons. Molecular dynamics simulation showed the different hydrogen bonding properties in the bulk and at the interface of water which 
influences stabilization or destabilization of species [8789 ] and provided information on the structure and energetics of the solvated of electrons $[33,90,91]$ as introduced in Section 3. However, applying empirical force fields and limited time frames to show dynamics in about 100 ps were seen to be a limiting factor of MD simulation in providing insightful data for the complex chemical kinetics required at the plasma-liquid interface [17].

Gopalakrishnan et al. presented detailed kinetic simulation results on solvated electrons and ions using particle-in-cell/Monte Carlo model (PIC/MC) coupled with a fluid model of an aqueous electrolyte [32] for the validation of experimental diagnostics results from Rumbach et al. [31]. Figure 6 shows the structure of the plasma-water interfacial region: solvated electron and ion density, electric field and space charge profile near the plasma interface with water. The model predicted that the solvated electron may be lost by the reaction with water within $10-20 \mathrm{~nm}$ for high average electron energy of $10 \mathrm{eV}$ at the interface, which is in good agreement with experimental estimation by Rumbach et al.
Plasma hydrodynamics simulation has provided significant understanding in plasma-bubble interactions with extensively detailed kinetics data, both for the gas and liquid phases, including studying the influence of applied voltage, size of the bubble and conductivity of liquid media [34-37, 71, 72, 92]. The model provides density and momenta of all included neutral and charged species, electron temperature by solving Poisson's equation, electron energy equation, transport equations for electron, ions and all neutral species. In order to present the plasma-liquid interaction, a second set of aqueous reactions and species are introduced in the model. The sticking coefficient for the diffusion loss of neutral species at the interface of gas and liquid is assigned according to the Henry's law equilibrium constant [35]. Different gas products can have significantly differences in their water solubility, hence a large difference in Henry's law constants may be required for example, $h$ value for $\mathrm{H}_{2} \mathrm{O}_{2}$, $\mathrm{HO}_{2}$ and $\mathrm{HNO}_{3}$ are in the range of $10^{5}-10^{6}$, in contrast, $\mathrm{N}_{2}, \mathrm{H}_{2}, \mathrm{O}_{2}, \mathrm{CO}$ and $\mathrm{NO}$ are only $10^{-2}$ [52]. Large $h$ values result in a high sticking coefficient and contribute to enhanced production rate of specific aqueous species

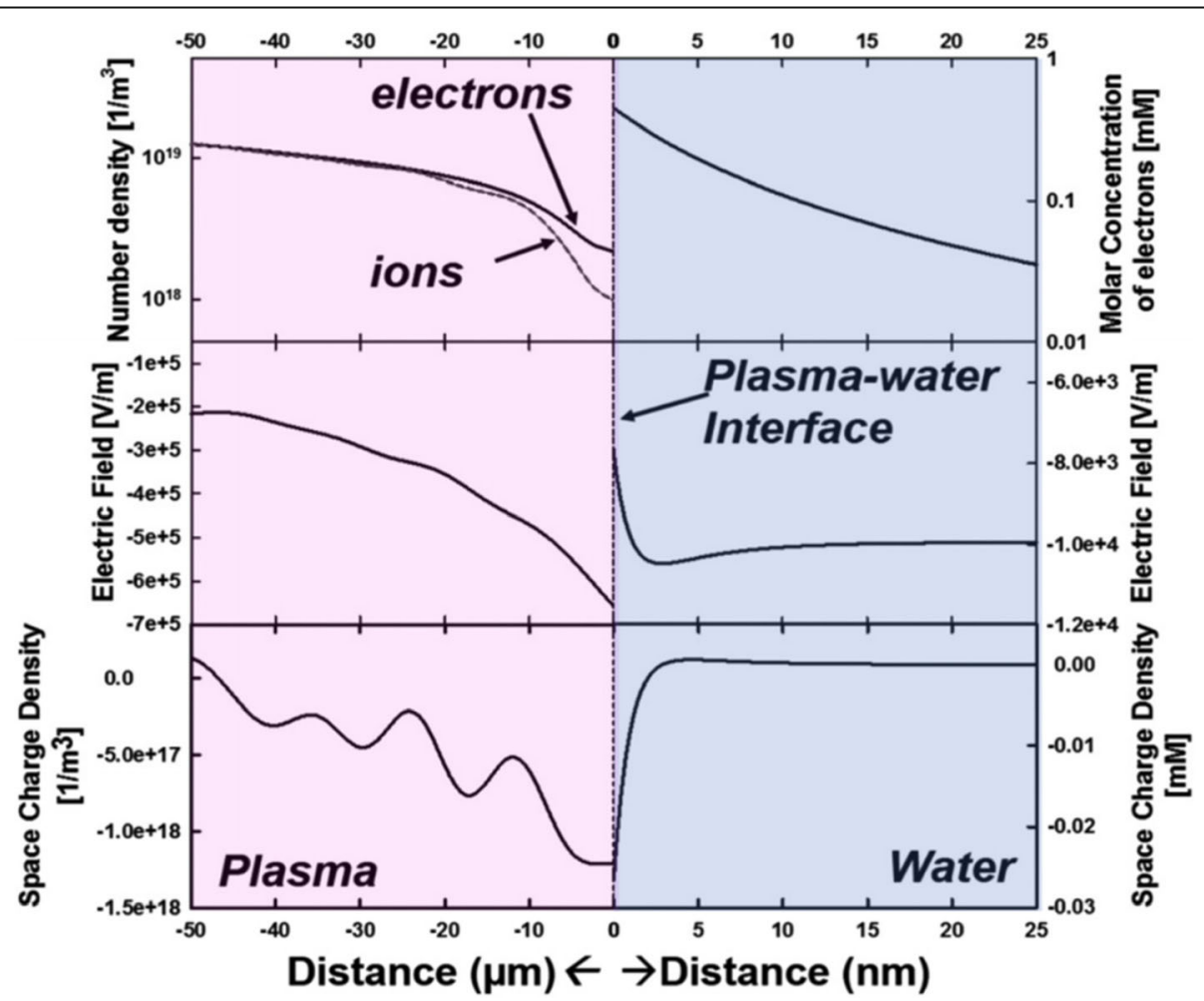

Fig. 6 Structure of the plasma-water interfacial region. Upper right: solvated electron density profile near the plasma interface with a salt concentration of $100 \mathrm{mM}$. The peak concentration at the water surface $(\sim 0.5 \mathrm{mM})$ corresponds to a number density of $\sim 10^{23} \mathrm{~m}^{-3}$. Upper left: plasma region near the water interface showing an electron-rich sheath with electron density at the interface in plasma $\sim 10^{18} \mathrm{~m}^{-3}$. Middle left: electric field profile in plasma near water. Middle right: electric field in water with the ratio of electric fields at the interface corresponding to the ratio of dielectric constants. Note the differences in length scales on the water and plasma side. Lower left: space charge profile in plasma near water. Lower right: space charge profile in water [32]. The spatial scales in the two phases as well as the units of space charge are different. Note that oscillations in the plasma space charge are from the PIC/MC solution [32] 
a)
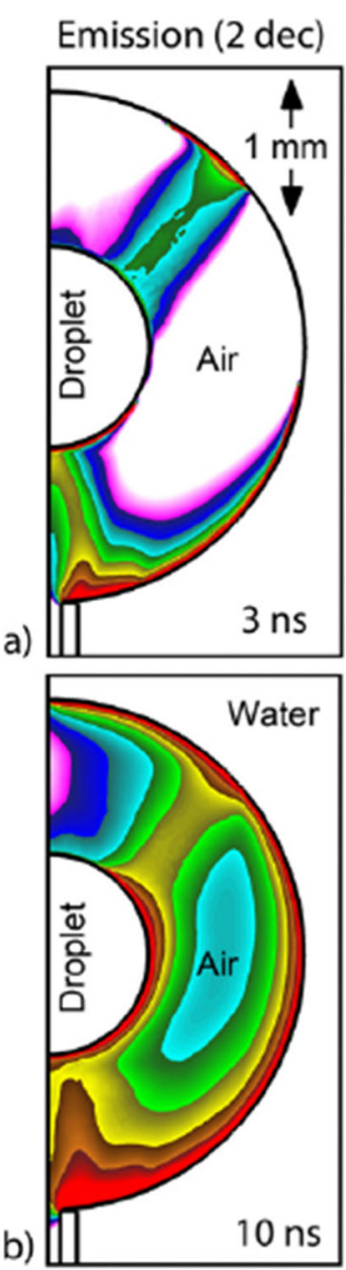

Min,

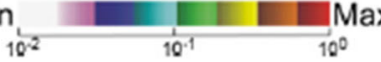

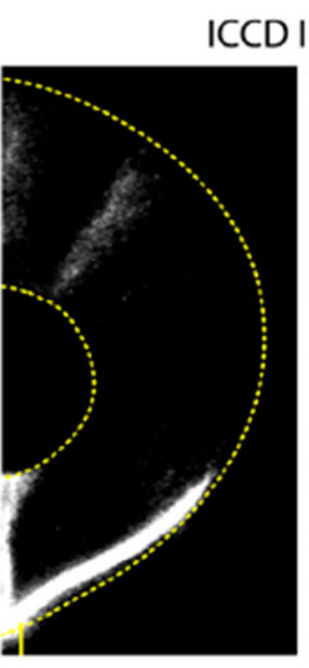

\section{mages}
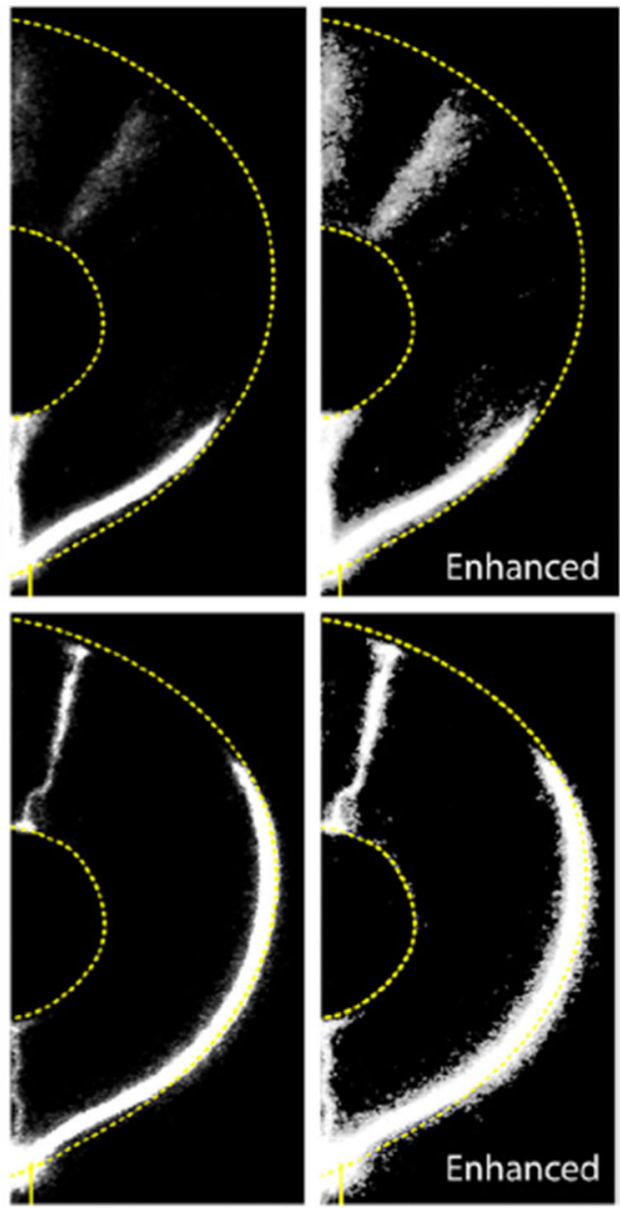

Fig. 7 Comparison of simulated optical emission and experimental observations a early and $\mathbf{b}$ late during the voltage pulse. The simulated emission is represented by time integrated emission from excited states of $\mathrm{N}_{2}, \mathrm{H}, \mathrm{OH}, \mathrm{O}$ and $\mathrm{O}_{2}$. The corresponding ICCD images had a 5 ns gate. The conductivity of both the water droplet and the surrounding water is $1.3 \times 10^{-2} \mathrm{~S} \mathrm{~cm}^{-1}$. Two versions of the ICCD images are shown-actual data and artificially enhanced to show more detail [36]

at similar diffusion coefficients of corresponding gas species and plasma-bubble discharge conditions. Leitz and Kushner [35] provided a detailed simulation result on the density profile of the different gas phase species within the discharge and solvated aqueous species in the water volume. At the given plasma condition, while $\mathrm{O}_{3}$ was the dominant species after the plasma was switched off and $\mathrm{N}_{2} \mathrm{O}$ was sustained in high density $10^{15} \mathrm{~cm}^{-3}$ in the gas phase, the density of $\mathrm{NO}_{3}{ }^{-}$(aq) showed a significant increase in water mainly due to the reaction to produce $\mathrm{HNO}_{\mathrm{x}(\mathrm{aq})}$ from $\mathrm{N}_{\mathrm{x}} \mathrm{O}_{\mathrm{y}(\mathrm{aq})}$ species followed by dissociation into $\mathrm{NO}_{\mathrm{x}}{ }^{-}$and $\mathrm{H}_{3} \mathrm{O}^{+}{ }_{(\mathrm{aq})}$ which are easily measurable quantities from the liquid water sample.

For a plasma-bubble geometry of $2 \mathrm{~mm}$ diameter attached to the high voltage electrode, Tian et al. demonstrated that the relaxation length of electron energy, and the diffusion rate of water vapour into the interior of the bubble can strongly influence the plasma dynamics and spatial distribution of the plasma discharge either the volumetric discharge or surface hugging discharge surrounding the interface of the bubble [37].

Figure 7 shows a comparison result of the model with the ICCD images from the experiment using a quasi-2D bubble apparatus. The simulated emission intensities used excited-states of $\mathrm{N}_{2}, \mathrm{H}, \mathrm{OH}, \mathrm{O}$ and $\mathrm{O}_{2}$, with the emission from $\mathrm{N}_{2}$ excited states predominant as expected. The highest emission intensity is observed at the initial filament between the electrode and the water droplet, followed by the advancing surface ionization wave along the surface of the outside gas bubble [36].

Lai et al. [60] conducted computation and experimental approaches to model and validate the effect of 


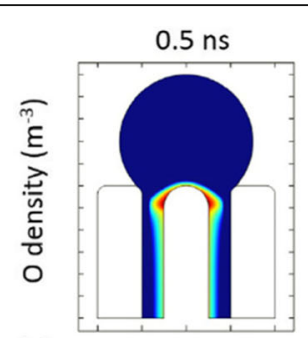

(a) $\operatorname{Max}=1.0 \times 10^{17}$

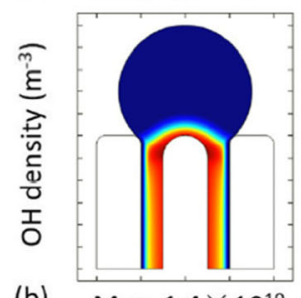

(b)

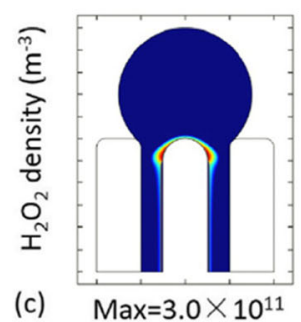

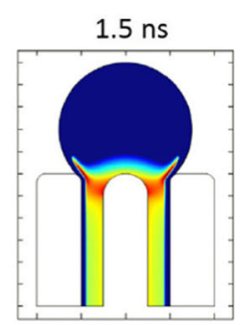

Max $=1.2 \times 10^{18}$

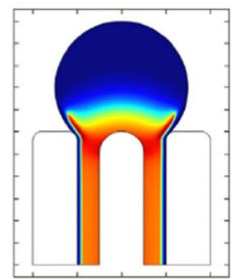

$\operatorname{Max}=1.2 \times 10^{20}$

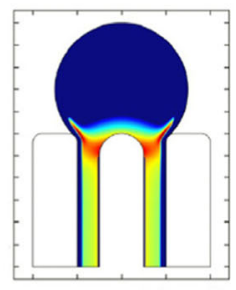

Max $=5.5 \times 10^{13}$

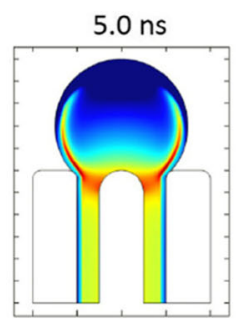

$\operatorname{Max}=2.5 \times 10^{19}$

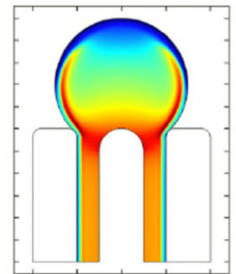

$\operatorname{Max}=9.2 \times 10^{20}$

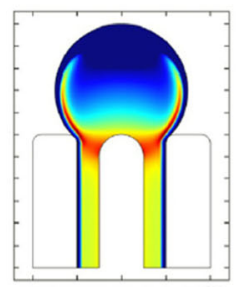

Max $=1.6 \times 10^{16}$
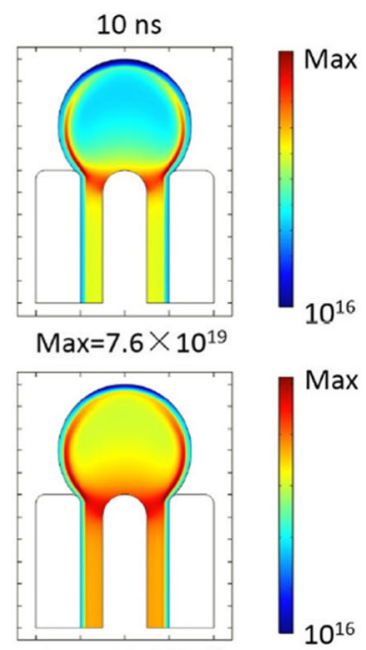

$\operatorname{Max}=2.2 \times 10^{21}$

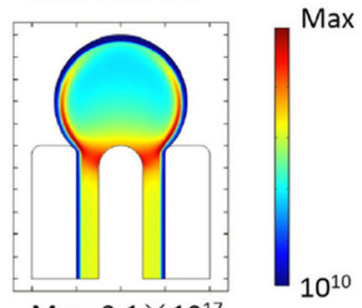

Max $=2.1 \times 10^{17}$

Fig. 8 Spatial distribution of $\mathbf{a} \mathrm{O}$ density, $\mathbf{b} \mathrm{OH}$ density and $\mathbf{c} \mathrm{H}_{2} \mathrm{O}_{2}$ density at $t=0.5,1.5,5.0$, and $10 \mathrm{~ns}$ within the underwater bubble [93]

electrical conductivity of the liquid on the propagation of ns pulsed discharges inside bubbles. The computational model showed that at low conductivity the effective electric field reduced in the bubble due to a voltage drop outside the bubble. At high conductivities, axial streamers were prevented by surface hugging (interfacial) streamers. In another modelling study, Babaeva et al. [72] indicated the importance of the conductivity of the liquid on the pattern of streamer propagation in bubbles. They reported that by increasing the conductivity the streamers propagated at the surface of bubble as a result of improved electric field across the boundary of the bubble. This is in agreement with experimental and simulation studies reported by Lai et al. [60]. Furthermore, Babaeva et al. [72] indicated the role of applied voltage and the size of bubble as additional factors affecting the transition of an axial streamer to a surfacehugging one.

Using a commercial multi-physics simulation tool, Yan et al. provided a spatial distribution of reactive species inside a plasma bubble including atomic $\mathrm{O}, \mathrm{OH}, \mathrm{H}_{2} \mathrm{O}_{2}$ as well as detailed electron energy and density distributions at different configurations of the relative positions of the electrode within the bubble as shown in Fig. 8 [93]. With further efforts of combining the diffusion and solvation reactions at the interface of the bubble and liquid chemical reactions within the bulk water as developed in a 1D model of Leitz and Kushner, it may enable innovative visualization of both the physics and chemistry for the entire domain including both gas and bulk liquid volume outside the bubble interface which would be a significant contribution to better understanding these complex plasma bubble discharges.

\section{Summary and outlook}

In this review, we have discussed the promising performance and benefits of plasma bubble discharge in the ranges of emerging applications related to plasma-liquid interactions. With intensified gas-to-liquid mass transfer, the approach may enhance the production and transport of aqueous reactive species with lower energy input in comparison to direct under water discharges or discharges over the water surface. Fast solvation of electrons and ions at the interface of the bubble is expected based on the results from a number of optical diagnostics and computational studies on plasma-liquid interaction and radiolysis. Different diffusion and solvation properties of chemically reactive neutral species is discussed with their temporal evolution and spatial distributions in the gas and liquid phases possible to calculate at different time scale using advanced plasma modelling as well as measured characteristics of electrons and ions. Investigations of the long-term chemistry using chemical probing techniques have contributed significantly to 
providing important information in understanding the plasma-bubble phenomena.

Plasma-bubbles combined with catalysis offer a promising new area of science for a range of chemical synthesis and conversion applications including sustainable resource recovery and conversion to higher-value upcycled products as well as heath, sterilization, cancer therapy and related applications.

As the utilization of the plasma-bubble as a sustainable approach for environmental applications, particularly water treatment, receives growing attention, it may be required to conduct studies to assess possible byproducts and their lifetimes in treated water to address any requirements set by regulatory bodies. Additionally, this technology has been offered as an alternative to conventional treatments extensive techno-economic assessments need to be carried out to demonstrate its advantages and improve its competitiveness compared to other technologies.

Many research questions remain unanswered due to the numerous challenges in mass transfer studies such as the significant interruption from both organic and inorganic impurities commonly present in the aqueous solutions. In order to improve the understanding on this multiphysics, multi-scale problem of dynamic plasma discharges in gas bubbles, it will require significant interdisciplinary research efforts between the fields of plasma physics and chemistry.

Despite the complexities and limited understanding of the physicochemical mechanisms found with plasmaliquid interactions, the unique potential of plasmabubble system of enabling efficient transport of energetic reactive species into a liquid medium offers a powerful route to sustainable chemistry.

\section{Acknowledgements}

$\mathrm{JH}$ and KO are grateful to QUT Centre for Materials Science for partial support.

\section{Authors' contributions}

K.O. and P.J. conceived of the presented idea. P.J. supervised the project. J.H., RW.Z., RS.Z., T.Z. and A.R. has compiled information from the published papers and wrote the different sections of this review. All authors discussed the draft and contributed to the final manuscript. The authors read and approved the final manuscript.

\section{Funding}

Not applicable.

\section{Availability of data and materials}

Not applicable.

\section{Declarations}

Ethical approval and consent to participate

Not applicable.

\section{Consent for publication}

Not applicable.

\section{Competing interests}

Authors Rezaeimotlagh and Cullen are associated with a plasma technology company, Plasmaleap Technologies, which provides plasma bubble technology.

\section{Author details}

${ }^{1}$ School of Chemical and Biomolecular Engineering, University of Sydney, Darlington, Sydney, New South Wales 2008, Australia. ${ }^{2}$ School of Chemistry and Physics and Centre for Materials Science, Queensland University of Technology, Brisbane, Queensland 4000, Australia. ${ }^{3}$ Plasmaleap Technologies, Merewether building, City Rd., Sydney, NSW 2008, Australia.

Received: 10 October 2021 Accepted: 3 November 2021

Published online: 18 November 2021

\section{References}

1. P.J. Bruggeman et al., Plasma-liquid interactions: a review and roadmap, Plasma Sources Sci. Technol. 25, 053002 (2016)

2. Q. Chen, J. Li, Y. Li, A review of plasma-liquid interactions for nanomaterial synthesis, J. Phys. D Appl. Phys. 48, 424005 (2015)

3. R. Zhou et al., Plasma-activated water: generation, origin of reactive species and biological applications, J. Phys. D Appl. Phys. 53, 303001 (2020)

4. B.S. Sommers, J.E. Foster, Plasma formation in underwater gas bubbles Plasma Sources, Sci. Technol. 23, 015020 (2014)

5. J. Foster et al., Perspectives on the Interaction of Plasmas With Liquid Water for Water Purification, IEEE Trans. Plasma Sci. 40, 1311 (2012)

6. J.S. Chang, Thermal Plasma Solid Waste and Water Treatments: A Critical Review, Int. J. of Plasma Environ. Sci. Tech. 3, 67 (2009)

7. A. Mai-Prochnow et al., Interactions of plasma-activated water with biofilms: inactivation, dispersal effects and mechanisms of action, NPJ Biofilms Microbiomes. 7, 11 (2021)

8. R. Zhou et al., Sustainable plasma-catalytic bubbles for hydrogen peroxide synthesis, Green Chemistry. 23, 2977 (2021)

9. R. Zhou et al., Microplasma Bubbles: Reactive Vehicles for Biofilm Dispersal, ACS Appl. Mater. Interfaces. 11, 20660 (2019)

10. J. Sun et al., A hybrid plasma electrocatalytic process for sustainable ammonia production, Energy Environ. Sci. 14, 865 (2021)

11. Y. Fang et al., Acoustic cavitation assisted plasma for wastewater treatment: Degradation of Rhodamine B in aqueous solution, Ultrason Sonochem. 52, 318 (2019)

12. R. Zhou et al., Plasmacatalytic bubbles using $\mathrm{CeO} 2$ for organic pollutant degradation, Chem. Eng. J. 403, 126413 (2021)

13. R. Zhou et al., Cold atmospheric plasma activated water as a prospective disinfectant: the crucial role of peroxynitrite, Green Chem. 20, 5276 (2018)

14. B.R. Locke, K.-Y. Shih, Review of the methods to form hydrogen peroxide in electrical discharge plasma with liquid water, Plasma Sources Sci. Technol. 20, 034006 (2011)

15. K. Tachibana, T. Nakamura, Comparative study of discharge schemes for production rates and ratios of reactive oxygen and nitrogen species in plasma activated water, J. Phys. D Appl. Phys. 52, 385202 (2019)

16. P. Bruggeman, C. Leys, Non-thermal plasmas in and in contact with liquids, J. Phys. D Appl. Phys. 42, 053001 (2009)

17. P.J. Bruggeman et al., Plasma-driven solution electrolysis, J. Appl. Phys. 129, 200902 (2021)

18. Š. Potocký, N. Saito, O. Takai, Needle electrode erosion in water plasma discharge, Thin Solid Films. 518, 918 (2009)

19. Y. Tu et al., Time-resolved imaging of electrical discharge development in multiple bubbles immersed in water, Plasma Process. Polym. 14, 1600259 (2017)

20. R. Zhou et al., Underwater microplasma bubbles for efficient and simultaneous degradation of mixed dye pollutants, Sci. Total Environ. 750, 142295 (2021)

21. R. Zhou et al., Plasma-enabled catalyst-free conversion of ethanol to hydrogen gas and carbon dots near room temperature, Chem. Eng. J. 382, 122745 (2020)

22. R. Zhou et al., Effects of Atmospheric-Pressure N2, He, Air, and O2 Microplasmas on Mung Bean Seed Germination and Seedling Growth, Sci Rep. 6, 32603 (2016)

23. T. Zhang et al., Degradation of cefixime antibiotic in water by atmospheric plasma bubbles: Performance, degradation pathways and toxicity evaluation, Chem. Eng. J. 421, 127730 (2021) 
24. Y. Tu et al., Time-resolved imaging of electrical discharge development in underwater bubbles, Phys. Plasmas. 23, 013507 (2016)

25. L. Turi, P.J. Rossky, Theoretical studies of spectroscopy and dynamics of hydrated electrons, Chem Rev. 112, 5641 (2012)

26. B.C.E.A. Garrett, Role of Water in Electron-Initiated Processes and Radical Chemistry: Issues and Scientific Advances, Chem. Rev. 105, 355 (2005)

27. D.M. Sagar, C.D. Bain, J.R.R. Verlet, Hydrated Electrons at the Water-Air Interface, J. Am. Chem. Soc. 132, 6917 (2010)

28. G.V. Buxton et al., Critical review of rate constants for reactions of hydrated electrons, hydrogen atoms and hydroxyl radicals in aqueous solutions, J. Phys. Chem. Ref. Data 17, 513 (1988)

29. J. Meesungnoen et al., Low-Energy Electron Penetration Range in Liquid Water, Radiat. Res. 158, 657 (2002)

30. N. Ottosson et al., Photoelectron spectroscopy of liquid water and aqueous solution: Electron effective attenuation lengths and emission-angle anisotropy. Journal of Electron Spectroscopy and Related Phenomena, J. Electron Spectrosc. Relat. Phenom. 177, 60 (2010)

31. P. Rumbach et al., The solvation of electrons by an atmospheric-pressure plasma, Nat Commun. 6, 7248 (2015)

32. R. Gopalakrishnan et al., Solvated electrons at the atmospheric pressure plasma-water anodic interface, J. Phys. D Appl. Phys. 49, 295205 (2016)

33. F. Uhlig, O. Marsalek, P. Jungwirth, Electron at the Surface of Water: Dehydrated or Not?, J Phys Chem Lett. 4, 338 (2013)

34. J. Kruszelnicki, A.M. Lietz, M.J. Kushner, Atmospheric pressure plasma activation of water droplets, J. Phys. D Appl. Phys. 52, 355207 (2019)

35. A.M. Lietz, M.J. Kushner, Air plasma treatment of liquid covered tissue: long timescale chemistry, J. Phys. D Appl. Phys. 49, 425204 (2016)

36. W. Ning et al., Propagation of positive discharges in an air bubble having an embedded water droplet, Plasma Sources Sci. Technol. 30, 015005 (2021)

37. W. Tian, K. Tachibana, M.J. Kushner, Plasmas sustained in bubbles in water: optical emission and excitation mechanisms, J. Phys. D Appl. Phys. 47, 055202 (2014)

38. D. Levko, A. Sharma, L.L. Raja, Kinetic modeling of streamer penetration into de-ionized water, Phys. Plasmas. 25, 033515 (2018)

39. Y. Minagawa et al., Analysis of effect of ion irradiation to liquid surface on water molecule kinetics by classical molecular dynamics simulation, Japan. J. Appl. Phys. 53, 010210 (2014)

40. S.T. Arnold et al., Murad E. Dynamics of hyperthermal $\mathrm{Kr}++\mathrm{H} 2 \mathrm{O}$ chargetransfer collisions, J. Chem. Phys. 102, 6110 (1995)

41. R.A. Dressler, R.H. Salter, E. Murad, Dynamics of the O+ + $\mathrm{H} 2 \mathrm{O}$ reaction and its implication for space-borne measurements, Planer. Space Ser. 40, 1695 (1992)

42. R.A. Dressler, E. Murad, Guided-ion beam measurements of $\mathrm{N}++\mathrm{H} 2 \mathrm{O}$ charge-transfer and chemical reaction channels, J. Chem. Phys. 100, 5656 (1994)

43. R.A. Dressler, R.H. Salter, E. Murad, Guided-ion beam measurements of the $\mathrm{X}++\mathrm{H} 2 \mathrm{O}(\mathrm{D} 2 \mathrm{O})(\mathrm{X}=\mathrm{Ar}, \mathrm{N} 2)$ collision systems, J. Chem. Phys. 99, 1159 (1993)

44. F. Tochikubo et al., Chemical reactions in liquid induced by atmosphericpressure dc glow discharge in contact with liquid, Japan. J. Appl. Phys. 53, 126201 (2014)

45. T. Verreycken et al., Validation of gas temperature measurements by OES in an atmospheric air glow discharge with water electrode using Rayleigh scattering, Plasma Sources Sci. Technol. 20, 024002 (2011)

46. Q. Xiong, Z. Yang, P.J. Bruggeman, Absolute $\mathrm{OH}$ density measurements in an atmospheric pressure dc glow discharge in air with water electrode by broadband UV absorption spectroscopy, J. Phys. D Appl. Phys. 48, 424008 (2015)

47. C.H. Chang, E.l. Franses, Langmuir-Hinshelwood kinetics for dynamic adsorption of surfactants at the air/water interface, Colloids Surf. 69, 189 (1992)

48. C.H. Chang, E.I. Franses, Adsorption dynamics of surfactants at the air/water interface: a critical review of mathematical models, data, and mechanisms, Colloids Surf. 100, 1 (1995)

49. G. Murdachaew et al., Nitrogen dioxide at the air-water interface: trapping, absorption, and solvation in the bulk and at the surface, Phys Chem Chem Phys. 15, 204 (2013)

50. M. Yusupov et al., Reactive molecular dynamics simulations of oxygen species in a liquid water layer of interest for plasma medicine, J. Phys. D Appl. Phys. 47, 025205 (2014)

51. D. Minakata et al., Development of a Group Contribution Method To Predict Aqueous Phase Hydroxyl Radical (HO•) Reaction Rate Constants, Environ. Sci. Technol. 43, 6220 (2009)
52. R. Sander et al., Henry's law constants, Pure Appl. Chem. 92, 1 (2020)

53. B. Poling, J. Prausnitz, J. O'Connell, The Properties of Gases and Liquids ((McGraw-Hill Education, New York 2001)

54. Y. Liu et al., Degradation of aniline in aqueous solution using non-thermal plasma generated in microbubbles, Chem. Eng. J. 345, 679 (2018)

55. M.-C. Wu et al., Dissolution enhancement of reactive chemical species by plasma-activated microbubbles jet in water, J. Phys. D Appl. Phys. 53, $485201(2020)$

56. J. Lin et al., The formation mechanism of aqueous hydrogen peroxide in a plasma-liquid system with liquid as the anode, The. Eur. Phys. J. D. 74, 80 (2020)

57. X. Wang et al., Micro hollow cathode excited dielectric barrier discharge (DBD) plasma bubble and the application in organic wastewater treatment, Separ. Purif. Technol. 240, 116659 (2020)

58. Y. Xin et al., Effects of electrode configurations, solution $\mathrm{pH}$, TiO2 addition on hydrogen production by in-liquid discharge plasma, Renewable Energy. $171,728(2021)$

59. B. Jiang et al., Review on electrical discharge plasma technology for wastewater remediation, Chem. Eng. J. 236, 348 (2014)

60. J. Lai, J.E. Foster, Time-resolved imaging of streamer formation inside gaseous bubbles in liquids, J. Phys. D Appl. Phys. 53, 025206 (2019)

61. A. Hamdan, J. Profili, M.S. Cha, Microwave Plasma Jet in Water: Effect of Water Electrical Conductivity on Plasma Characteristics, Plasma Chem. Plasma Process. 40, 169 (2020)

62. P. Vanraes, Nikiforov A.Y., and Leys C., Chapter 16. Electrical Discharge in Water Treatment Technology for Micropollutant Decomposition in Plasma science and technology-progress in physical states and chemical reactions. (Intech Open book, 2016)

63. R.P. Joshi, S.M. Thagard, Streamer-like electrical discharges in water: Part II. Environmental applications, Plasma Chem. Plasma Process. 33, 17 (2013)

64. J. Li, M. Sato, T. Ohshima, Degradation of phenol in water using a gas-liquid phase pulsed discharge plasma reactor, Thin Solid Films. 515, 4283 (2007)

65. B. Sun, M. Sato, J.S. Clements, Optical study of active species produced by a pulsed streamer corona discharge in water, J. Electrost. 39, 189 (1997)

66. B. Yang, L.-C. Lei, M.-H. Zhou, Effects of the liquid conductivity on pulsed high-voltage discharge modes in water, Chinese Chem. Lett. 15, 1215 (2004)

67. P. Vanraes, A. Bogaerts, Plasma physics of liquids-A focused review, Appl. Phys. Rev. 5, 031103 (2018)

68. Y.-S. Chen et al., Pulsed high-voltage discharge plasma for degradation of phenol in aqueous solution, Separ. Purif. Technol. 34, 5 (2004)

69. B. Jiang et al., Degradation of azo dye using non-thermal plasma advanced oxidation process in a circulatory airtight reactor system, Chem. Eng. J. 204, 32 (2012)

70. B.S. Sommers et al., Observations of electric discharge streamer propagation and capillary oscillations on the surface of air bubbles in water, J. Phys. D Appl. Phys. 44, 082001 (2011)

71. N.Y. Babaeva et al., Streamer breakdown in elongated, compressed and tilted bubbles immersed in water, J. Phys. D Appl. Phys. 50, 364001 (2017)

72. N.Y. Babaeva, M.J. Kushner, Structure of positive streamers inside gaseous bubbles immersed in liquids, J. Phys. D Appl. Phys. 42, 132003 (2009)

73. S.Y. Yoon et al., Mutual Interaction between Plasma Characteristics and Liquid Properties in AC-driven Pin-to-Liquid Discharge, Sci Rep. 8, 12037 (2018)

74. D. Schröder et al., Schulz-von der Gathen V. Influence of target surfaces on the atomic oxygen distribution in the effluent of a micro-scaled atmospheric pressure plasma jet, Plasma Sources Sci. Technol. 21, 024007 (2012)

75. S. Yatom et al., Nanosecond pulsed humid Ar plasma jet in air: shielding, discharge characteristics and atomic hydrogen production, J. Phys. D Appl. Phys. 50, 415204 (2017)

76. T. Verreycken, N. Sadeghi, PJ. Bruggeman, Time-resolved absolute OH density of a nanosecond pulsed discharge in atmospheric pressure $\mathrm{He}-\mathrm{H} 2 \mathrm{O}$ : absolute calibration, collisional quenching and the importance of charged species in OH production, Plasma Sources Sci. Technol. 23, 045005 (2014)

77. A.F.H. van Gessel et al., aser scattering on an atmospheric pressure plasma jet: disentangling Rayleigh, Raman and Thomson scattering, Plasma Sources Sci. Technol. 21, 015003 (2012)

78. P.J. Bruggeman et al., Gas temperature determination from rotational lines in non-equilibrium plasmas: a review, Plasma Sources Sci. Technol. 23 023001 (2014) 
79. N. Hodnik, G. Dehm, K.J. Mayrhofer, Importance and Challenges of Electrochemical in Situ Liquid Cell Electron Microscopy for Energy Conversion Research, Acc. Chem. Res. 49, 2015 (2016)

80. A. Hussein Sheik et al., Electrokinetic Transport of a Charged Dye in a Freely Suspended Liquid Film: Experiments and Numerical Simulations, Langmuir. 36, $1183(2020)$

81. T. Ito, T. Izaki, K. Terashima, Development of plasma chip, Surf. Coat. Technol. 133-134, 497 (2000)

82. S. Kumagai et al., Plasma-on-Chip : device for non-thermal atmospheric pressure plasma irradiation to single cells, Electron. Commun. Japan. 103, 43 (2020)

83. J.B. Fox, Kinetics and mechanisms of the Griess reaction, Anal. Chem. 51 1493 (1979)

84. K. Oehmigen et al., The Role of Acidification for Antimicrobial Activity of Atmospheric Pressure Plasma in Liquids, Plasma Processes Polymers. 7, 250 (2010)

85. M.J. Pavlovich et al., Ozone correlates with antibacterial effects from indirect air dielectric barrier discharge treatment of water, J. Phys. D Appl. Phys. 46 $145202(2013)$

86. J. Staehelin, J. Hoigne, Decomposition of ozone in water in the presence of organic solutes acting as promoters and inhibitors of radical chain reactions, Environ. Sci. Technol. 19, 1206 (1985)

87. S. Chalmet, M.F. Ruiz-Lopez, The structures of ozone and HOx radicals in aqueous solution from combined quantum/classical molecular dynamics simulations, J. Chem. Phys. 124, 194502 (2006)

88. M.T. Martins-Costa et al., Reactivity of atmospherically relevant small radicals at the air-water interface, Angew Chem. Int. Ed Engl. 51, 5413 (2012)

89. M.T.C. Martins-Costa, M.F. Ruiz-López, Molecular dynamics of hydrogen peroxide in liquid water using a combined quantum/classical force field, Chem. Phys. 332, 341 (2007)

90. O. Marsalek et al., Dynamics, and Reactivity of Hydrated Electrons by Ab Initio Molecular Dynamics, Acc. Chem. Res 45, 23 (2012)

91. L.D. Jacobson, J.M. Herbert, Theoretical characterization of four distinct isomer types in hydrated-electron clusters, and proposed assignments for photoelectron spectra of water cluster anions, J. Am. Chem. Soc. 133, 19889 (2011)

92. N.Y. Babaeva, D.V. Tereshonok, G.V. Naidis, Initiation of breakdown in bubbles immersed in liquids: pre-existed charges versus bubble size, J. Phys. D Appl. Phys. 48, 355201 (2015)

93. W. Yan et al., Numerical investigation of underwater discharge generated in a single helium bubble at atmospheric pressure, Phys. Plasmas. 26, 023504 (2019)

\section{Publisher's Note}

Springer Nature remains neutral with regard to jurisdictional claims in published maps and institutional affiliations. 